\title{
Supporting Future Career of Autistic Learners via Technology: Design and Development of iBakery Courseware
}

\author{
Faaizah Shahbodin ${ }^{1^{*}}$, Meylinda Maria ${ }^{2}$, Che Ku Nuraini Che Ku Mohd ${ }^{3}$, Nurul \\ Amiera Jaafar ${ }^{4}$
}

${ }^{1}$ Centre for Academics Excellence and Scholarship, Universiti Teknikal Malaysia Melaka, Hang Tuah Jaya, Durian Tunggal, Melaka, 76100, MALAYSIA

${ }^{2,4}$ Faculty of Information and Communication Technology, Universiti Teknikal Malaysia Melaka, Hang Tuah Jaya,
Durian Tunggal, Melaka, 76100, MALAYSIA

${ }^{3}$ Centre for Research and Innovation Management, Universiti Teknikal Malaysia Melaka, Hang Tuah Jaya, Durian Tunggal, Melaka, 76100, MALAYSIA

DOI: https://doi.org/10.30880/jtet.2019.11.03.013

Received $15^{\text {th }}$ Jan 2019; Accepted $17^{\text {th }}$ September 2019; Available online $30^{\text {th }}$ September 2019

\begin{abstract}
The evolution of education affects the style and approach of teaching and learning. Education 4.0 as the current evolution in education focuses on the students and the usage of technology. iBakery as a form of iBook is one of the technology implementations in education for Autistic students. iBakery is an Autistic user-friendly courseware which provides a set of instructions needed in baking activity. By concentrating on the interface, content presentation, and flow of the system, iBakery could help Autistic students to learn about bakery in a fun way. From the qualitative testing which has been conducted towards target users, results show positive feedbacks on iBakery from both teachers and Autistic students. It is believed that iBakery could help Autistic students to gain their baking skills which could be applied in their future life as a chance of independent living and career opportunity.
\end{abstract}

Keywords: Autistic learners, career development, education 4.0

\section{Introduction}

Education is an important thing which is needed by everyone. It could change and evolve based on what is happening at the present time. One of the biggest factors that influence education comes from the industrial side, known as Industrial Revolution 4.0 (IR 4.0). There is a similar term in education known as Education 4.0 which follows the concept of IR 4.0. Education 4.0 focuses on responding to the needs of IR4.0 where human and technology are aligned to enable new possibilities (Hussin, 2018). There will be some inevitable shifts of replacing some of human workforces with technology, for example the robotic technology. This will eventually affect the next generation in terms of jobs availability, especially for special needs generation who already have limited choice of jobs.

In Education 4.0, teaching and learning process focus more on the students instead of the teachers. The use of technology is crucial in Education 4.0 era in order to allow students to learn individually (Maria et al., 2018). Technology used in teaching and learning process could be in any form of courseware, mobile app, MOOC, interactive book, augmented reality, virtual reality, and many more. In order to implement Education 4.0 and follow the current trend of IR 4.0, technology should be used by every students including the special needs students. Special needs students vary based on their type of disorders and disabilities. This paper focuses on the Autistic students.

Autism or known as Autism Spectrum Disorder (ASD) is a type of disorder related to brain development which affect the presence of social cognition, communication, and imagination (Keen, Reid \& Arnone, 2010). The three impairments are considered as the most serious developmental disabilities which could be noticed within the first years of life (Noor, Shahbodin, \& Pee, 2012). 
Autism could also be characterized by restricted or repetitive behavioural patterns (Zajic et al., 2018). Autistic children tend to play something repetitively and more focused on object oriented rather than people (DeFilippis \& Wagner, 2016). Usually, Autistic children give full attention towards certain objects or unusual interesting topics. The repetitive behavior can help in learning process, when combined with certain subject of interest, Autistic children tend to gain more information easily including their skill development.

Exposing them to technology is a brilliant approach for Autistic students as long as the technology could fit the basic requirement and needs of the students. Technology which uses natural interfaces that involves gestures as the input from the user will allow user to interact with the system easily (Hachaj \& Baraniewicz, 2015). Interactive and interesting way of learning is proven to be efficient way to help the children to memorize which could lead to basic skill development (Xhemajli, 2016).

Autism could be diagnosed in the early stage of an individual's life (Clark et al., 2018). The diagnosis could help to identify the right time for technology intervention, which in most cases - the sooner the better. The right intervention at the right time for autistic children may result in the improvement of many aspects in Autistic children's life such as learning, communicating, interacting, and organizing tasks. However, many of Autistic children still face problems in their life where in worse cases, it continues up to their adulthood especially in social life and independent living (Anderson et al., 2018). Among the problems faced by Autistic people when they become independent as adult are hardship in finding jobs and lack of trust from the employers. Based on this case, iBakery is proposed as an implementation of exposing technology to the Autistic students. It also focuses on helping the Autistic students to gain basic knowledge and skills in baking which could be useful in their future life.

\section{2. iBakery}

iBakery is an electronic courseware or an application which adapts the step-by-step instructions for baking. It is developed to help the Autistic students from Sekolah Menengah Bukit Katil to learn about baking in a better learning platform interactively. iBakery provides the complete steps of baking a sausage bun. There are three main sections in iBakery; Ingredients and Baking Tools, How to Use the Tools, and Steps. As an additional feature, there is a simple quiz at the end of the courseware. It consists few questions related to things used in the steps with multiple choice answers.

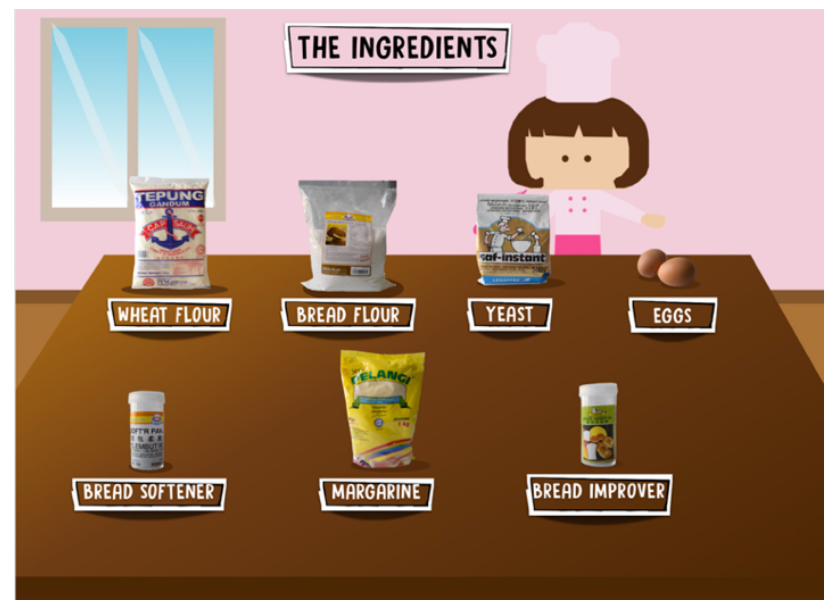

Fig. 1 - List of ingredients in iBakery

First section of iBakery presents the list of ingredients and tools needed in baking. All of the ingredients are demonstrated in this section as shown in Figure 1. Interaction from the user could be found in a simple description of the item that appears once the item is clicked. The images used in this section are real life images, thus it is easier for the Autistic students to relate with the actual items. This helps them to remember the items. The next section consists of list of tools used in baking. Here, iBakery informs the set of tools used along with the description of each tools that can be retrieved by clicking on the image. 


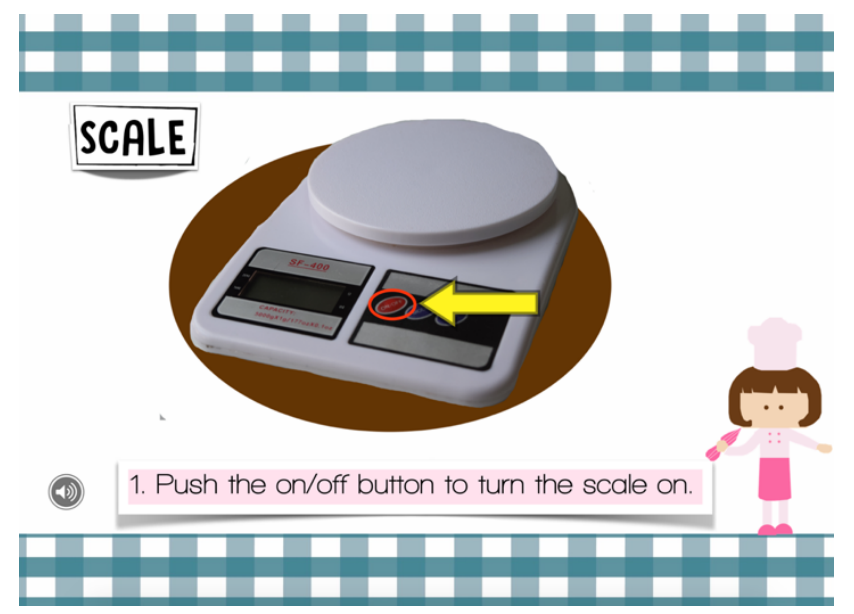

Fig. 2 - How to Use the Tools

Figure 2 shows the second section of iBakery which demonstrates how to use the tools needed in baking process. This section uses real life image of each tools with the detail steps on how to use it. The detail description is in the form of text and voice. This step uses voice to describe the steps to make it easier for Autistic students who are not good in reading.

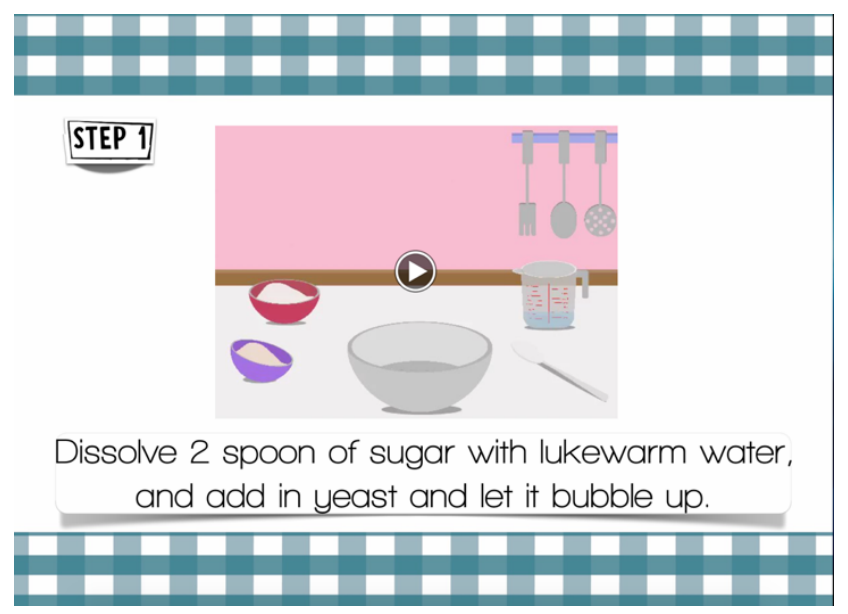

Fig. 3 - Steps of Baking Sausage Bun

Figure 3 shows the third section of iBakery which demonstrates the steps of baking a sausage bun. This section uses two approaches; one in 2D animation videos and the other one is in written text of steps. The first part of this section explains all the ingredients' measurement. Then it is followed by the steps in 2D animation videos. The last part shows the detail steps in texts.

\section{Methodology}

The methodology used for iBakery development is ADDIE model which has five main phases to be followed; Analysis, Design, Development, Implementation, and Evaluation. ADDIE model has been considered as an essential element in educational development and training programs (Muruganantham, 2015). Hence, this model is suitable for this project as it includes the development of the product.

Analysis; Problem of this study is defined as the difficulties faced by the Autistic children in learning activities which involve a series of steps, such as baking. The main objective to be achieved is to draw the Autistic students' focus and attention. The next step is requirement analysis which focuses on the user and technical part. In user part, it focuses on things that are needed to engage the Autistic children, which in this study is by implementing interactive elements such as images and animation videos to deliver the information. Technical part covers the platform and application chosen, which is iBook on iPad platform. It is chosen because it could deliver interactive elements needed in this study.

Design \& Development; iBakery in the form of iBook consists of three main sections which are; Baking Tools and Ingredients, How to Use the Tools, and Steps. The design includes the image, text, audio and animation to describe the information. All of the information is collected directly from the school including the recipe and ingredients used. 
Implementation; The main purpose of iBook is to attract the students to learn in a fun and interactive way. The teachers take part in the implementation process by going through the iBook to get the idea of the contents before they proceed to let the students access the iBook themselves. The students are required to do small quiz at the end of the session in the iBook.

Evaluation; The testing phase is conducted to get the evaluation of iBakery system. It measures the effectiveness and efficiency of the iBakery. Data are collected from the testers - both teachers and Autistic students. The teachers are asked to fill up the questionnaire regarding the product, while the students are asked the questions from questionnaire verbally along with direct observation to interpret their answers.

iBakery target users are divided into two groups which are; the teachers and students under Special Education Unit. The testing was conducted in Sekolah Menengah Bukit Katil which involved 2 teachers and 8 Autistic students. Questionnaires are used in order to rate the effectiveness of iBakery along with the observation of the direct responds from participants. Data collection was conducted in the same day with the testing where questionnaires were distributed to the teachers and students at the end of the session.

\section{Results and Discussions}

iBakery has been tested on the target users which are the Autistic students and special education teachers. Total participants are 10;8 Autistic students and 2 teachers. The instrument used for the testing is questionnaire which are distributed to the observer through direct observation. There are also questions to the target users to be answered verbally.

The following Table 1, 2, and 3 show the results of the questions given during the testing. The questions are given by the tester in questionnaire form. The results are categorized into three main concerns; (i) Content Flow, (ii) Content Comprehension, (iii) Content Interest.

Table 1 - Content Flow

\begin{tabular}{lccc}
\hline Focus Point & Agree & $\begin{array}{c}\text { Slightly } \\
\text { Agree }\end{array}$ & Disagree \\
\hline Clear Guide & 8 & 2 & - \\
Easy Ingredients & 8 & 2 & - \\
Identification & 9 & 1 & - \\
Easy Tools Identification & 10 & - & - \\
Suitable Learning & & & 2 \\
Platform & 8 & - & 2 \\
Suitable Device & & & \\
\hline
\end{tabular}

Table 1 shows the results of content flow focus points. The finding above shows more than half of the participants agreed that iBakery is a user-friendly application where they do not have any problem while using it. The interface of iBakery is clean with bright colour as the background that does not disturb the contents. 2D cartoon character is also used as a chef in the application to attract the Autistic students in order to engage their focus. Other than that, to maintain the focus, iBakery also uses big image as well as easy-to-read font and straight to the point instructions. iBakery also has quiz section which could provide the idea on how good the Autistic students grasp the info given on making sausage bun. However, based on result, there are two participants who disagreed that the product is a suitable device because the school does not provide any iPad to be used in the classroom. Hence, they found it quite hard to access iBakery if there is no iPad available during the class.

Table 2 - Content Comprehension

\begin{tabular}{lccc}
\hline Focus Point & Agree & $\begin{array}{c}\text { Slightly } \\
\text { Agree }\end{array}$ & Disagree \\
\hline Easy to Follow & 7 & 1 & 2 \\
Interesting Animation & 10 & - & - \\
Understandable & 10 & - & - \\
Animation & & & - \\
Recap Helps & 9 & 1 & - \\
Fun and Interesting & 10 & - & \\
\hline
\end{tabular}

While result in Table 2 points out the overall understanding of the participants during the use of iBakery. Few participants could not use the iBakery application easily. The reason is because they are not quite familiar with the use of iPad. However, most of the Autistic students being tested are exposed to using gadgets. Due to this, they can easily adapt on the usage of new technology. Hence, there are less difficulties for them to operate the iBakery. 
The participants' interest towards iBakery is shown in Table 3, where majority of them agreed that iBakery has interesting design, content, activity, along with the text display and neat content. All the results above indicate that the participants, especially the Autistic students are interested in usage of iBakery. It draws their attention and focus on the content, ease the absorption of knowledge while they are enjoying the process. It is proven that Autistic students are always hard to focus on certain things and to maintain the focus for a long time. This is why iBakery is designed with cartoonish look as its interface in order to engage the Autistic students. The set of instructions are presented in two ways; one by using 2D animation and another one by using written instruction with images. For students who have difficulties in reading, they could play the 2D animation and listen to the instructions, while for the rest of students who like to read could use the other way by reading all the instructions given along with the images for better visualization.

Table 3 - Content Interest

\begin{tabular}{lccc}
\hline Focus Point & Agree & $\begin{array}{c}\text { Slightly } \\
\text { Agree }\end{array}$ & Disagree \\
\hline Interesting Design & 6 & 2 & 2 \\
Interesting Content & 10 & - & - \\
Interesting Activity & 9 & 1 & - \\
Easy Text & 9 & 1 & - \\
Neat Content & 10 & - & - \\
\hline
\end{tabular}

Based on the results above, iBakery is a user-friendly technology for both teachers and Autistic students. Autistic students and teachers have no significant problem to run and interact with iBakery. There are only few students who are not familiar enough with the platform and have a little bit of confusion on how to interact with it. However, after being instructed carefully, they are able to run and interact with iBakery easily.

\section{Conclusion}

iBakery is presented in both animation videos and images which show the step-by-step instructions. The Autistic students along with their teachers who have tested the iBakery found that it is an interesting and fun way to learn how to bake by watching the 2D animation videos.Findings show that iBakery is a user-friendly courseware which could draw attention of the Autistic students as the main target and allow them to learn how to bake in an interactive and fun way. The interface is suitable for Autistic students because it does not have many elements on each screen which could distract the Autistic student's concentration. It also has easy navigation which eliminates confusion to use, combined with big and clear font for easier letter identifying and reading. The instructions given are also straight forward and clear from beginning to the end. It helps the Autistic students to grasp the basic knowledge and skill of baking.

The results could also be related to current situation in education where the technology is needed to be exposed to students including special needs students. Technology could help ease the teaching and learning process of special needs students. The target user for this iBakery, which is Autistic students, appeared to be excited in using iBakery and also assured the researcher that they could easily understand the flow of baking sausage bun. As an added bonus, this could be opportunity for them to apply the skill in their real life as an effort to be independent in the future.

The use of iBakery is hoped to help Autistic students, not only for their teaching and learning process of baking subject, but also to help them to be able to study by themselves. In relation to the IR 4.0, the implementation of iBakery in class could help them to practice the skills in baking, which could be used by them in the future. In case of lack in jobs availability, Autistic students can utilise their knowledge in baking to survive on their own. They could use the skills to start a baking business on their own or even turn to become entrepreneur themselves.

However, further work for improvement is still needed to achieve better results and impact on the actual targets. Changes in the structure and flow of the iBakery modules could help targets to easily follow the instructions. Since iBakery is a linear one-way flow of contents, improvement can be made to allow the users to have freedom in controlling the content flow. This would help them to enjoy more in using iBakery.

Another improvement could be in terms of the product platform, materials (images, videos, animations), and words of instruction. Product platform could be changed since there is lack of iPad users among target users in this study. The materials especially the $2 \mathrm{D}$ animation, could be changed into a real video instead because the visualization of $2 \mathrm{D}$ animation could not represent everything compared to real-life image. While the words of instruction could be changed in terms of the font style and placement. 


\section{Acknowledgement}

Authors would like to express deepest gratitude towards Universiti Teknikal Malaysia Melaka (UTeM) and everyone who have helped and participated in this study. This study is sponsored by UTeM Fund under grant FRGS/1/2016/ICT01/UTEM/02/2/F00326.

\section{References}

Anderson, K. A., Sosnowy, C., Kuo, A. A., \& Shattuck, P. T. (2018). Transition of Individuals with Autism to Adulthood: a Review of Qualitative Studies. Pediatrics, 141(Supplement 4), S318-S327.

Clark, M. L. E., Vinen, Z., Barbaro, J., \& Dissanayake, C. (2018). School Age Outcomes of Children Diagnosed Early and Later with Autism Spectrum Disorder. Journal of autism and developmental disorders, 48(1), 92-102.

DeFilippis, M., \& Wagner, K. D. (2016). Treatment of Autism Spectrum Disorder in Children and Adolescents. Psychopharmacology Bulletin, 46(2), 18.

Hachaj, T., \& Baraniewicz, D. (2015). Knowledge Bricks-Educational Immersive Reality Environment. International Journal of Information Management, 35(3), 396-406.

Hussin, A. A. (2018). Education 4.0 Made Simple: Ideas For Teaching. International Journal of Education and Literacy Studies, 6(3), 92-98.

Keen, D.V., Reid, F., \& Arnone, D. (2010). Autism, Ethnicity and Maternal Immigration. The British Journal of Psychiatry: The Journal of Mental Science, 196 4, 274-81.

Maria, M., Shahbodin, F., \& Pee, N. C. (2018). Malaysian Higher Education System Towards Industry 4.0-Current Trends Overview. In AIP Conference Proceedings (Vol. 2016, No. 1, p. 020081).

Muruganantham, G. (2015). Developing of E-Content Package by Using ADDIE Model. International Journal of Applied Research, 1(3), 52-54

Noor, H. A. M., Shahbodin, F., \& Pee, N. C. (2012). Serious Game for Autism Children: Review of Literature. World Academy of Science, Engineering and Technology. International Journal of Social, Behavioral, Educational, Economic, Business and Industrial Engineering, 6(4), 554-559.

Xhemajli, A. (2016). The Role of The Teacher In Interactive Teaching. International Journal of Cognitive Research in Science, Engineering and Education (IJCRSEE), 4(1), 31-38.

Zajic, M. C., McIntyre, N., Swain-Lerro, L., Novotny, S., Oswald, T., \& Mundy, P. (2018). Attention and Written Expression in School-Age, High-Functioning Children with Autism Spectrum Disorders. Autism, 22(3), 245-258. 